\title{
Adaptabilidade e estabilidade produtiva de genótipos de tomateiro em condições de temperatura elevada ${ }^{1}$
}

\author{
Adaptability and productive stability of tomato genotypes in high temperature
}

\author{
Miréia Aparecida Bezerra Pereira ${ }^{2 *}$, Sebastião Márcio de Azevedo ${ }^{3}$, Gilson Araújo de Freitas ${ }^{4}$, Gil Rodrigues \\ dos Santos $^{4}$ e Ildon Rodrigues do Nascimento ${ }^{4}$
}

\begin{abstract}
Resumo - O objetivo desta pesquisa foi avaliar a adaptabilidade e estabilidade de 15 genótipos de tomateiro na região de Gurupi, estado do Tocantins. Para o efeito, foram conduzidos dois experimentos em blocos casualizados, com três repetições, em casa de vegetação no verão (dezembro a março) e no campo durante o inverno (junho a setembro), com 15 genótipos experimentais de tomateiro: quatro do tipo longa vida mutantes de amadurecimento rin comerciais e pré-comerciais que foram: Tyler, Rebeca, Carmem e AF 13527; nove do tipo longa vida estrutural comerciais e précomerciais: Lumi, Débora Max, Michelli, Tammy, AF 12525, AF 11097, AF 13363, AF 13364 e AF 13525; e dois de frutos normais: Santa Clara e Drica. Os genótipos tipo longa vida Tyler, Rebeca, AF 13364, AF 13525, AF 13527 foram classificados como de estabilidade e adaptabilidade ampla para a característica produtividade comercial de frutos. Quanto ao peso médio comercial de frutos, os genótipos Tyler, Michelli e AF 11097, foram os únicos que apresentaram ampla adaptabilidade nas condições avaliadas.
\end{abstract}

Palavras-chave - Solanum lycopersicum L. Plantas-efeito da temperatura. Plantas-produtividade.

\begin{abstract}
The objective of this work was to evaluate the adaptability and stability of 15 tomato genotypes in the area of Gurupi, Tocantins. The experiments were carried out in two environments [greenhouse: in the summer (December to March) and in open field: winter (June to September)], with 15 experimental tomato genotypes, being: four of the type long shelf life commercial ripening mutants and pre-commercial (rin): Tyler, Rebeca, Carmem and AF 13527; nine of the type long shelf life structural commercials and pre-commercial: Lumi, Débora Max, Michelli, Tammy, AF 12525, AF 11097, AF 13363, AF 13364 and AF 13525; and two of normal fruits: Santa Clara and Drica, in randomized block design with three repetitions. The long life genotypes e Tyler, Rebeca, AF 13364, AF 13525, AF 13527 it were classified as of stability and wide adaptability and wide adaptability for yield. For the average weight of commercial fruits, the genotypes Tyler, Michelli and AF 11097 presented wide adaptability to the evaluated environments.
\end{abstract}

Key words - Solanum lycopersicum L. Plant-effect of the temperature. Plant-productivity.

\footnotetext{
*Autor para correspondência

${ }^{1}$ Recebido para publicação 13/10/2010; aprovado em 19/10/2011

Parte da Dissertação de Mestrado do primeiro autor apresentada à Universidade Federal do Tocantins/UFT

${ }^{2}$ Departamento de Ciência, Tecnologia \& Inovação-Propesq, Fundação Centro Universitário UnirG, Gurupi-TO, Brasil, mireiaaparecida@ yahoo.com.br ${ }^{3}$ Sakata Seed Sudamérica, Setor de Melhoramento Genético Hortaliças/Tomate, Bragança Paulista_SP, sebastiao.azevedo@sakata.com.br ${ }^{4}$ Departamento de Agronomia, Universidade Federal do Tocantins, Campus de Gurupi; Gurupi-TO, Brasil, freitas@uft.edu.br, gilrsan@uft.edu.br, ildon@uft.edu.br
} 


\section{Introdução}

O tomateiro (Solanum lycopersicum L.) é uma das hortaliças mais difundidas no mundo, sendo cultivado nas mais diferentes latitudes geográficas em campo ou em cultivo protegido, sob diferentes níveis de tecnologia. No Brasil, a cultura do tomateiro ocupa o segundo lugar, em produção, entre todas as hortaliças cultivadas (SHIRAHIGE, 2009).

Entre os tipos de cultivares, os tomates do tipo longa vida têm sido cultivados especialmente na região CentroSul do Brasil, especialmente nos estados de Goiás, São Paulo e Minas Gerais, abastecendo tanto os mercados dessas regiões, como também os mais distantes, especialmente a região Norte do Brasil. Os tomates do tipo longa vida têm ganhado destaque devido à maior vida pós-colheita (DELLA VECCHIA; KOCH, 2000), podendo ser enviado a regiões mais distantes. Esses tomates podem ser do tipo estrutural e, ou, com mutantes que retardam a maturação dos frutos (genes com alelos rin, alc e, ou, nor) (CÁ et al., 2006).

Devido à flexibilidade que podem oferecer ao produtor no momento da colheita, tomates do tipo longa vida podem representar uma alternativa para produção de tomate em regiões com temperaturas mais elevadas, pois a colheita dos frutos é realizada no estádio de maturação do tipo breaker, aumentando o tempo desde a colheita até a comercialização dos frutos (DELLA VECCHIA; $\mathrm{KOCH}, 2000)$. O fato dos frutos serem colhidos no estádio de maturação fisiológica do tipo breaker, pode possibilitar a obtenção de frutos com coloração semelhante aos produzidos em regiões de temperaturas mais amenas, pois a maturação dos frutos ocorre em pós-colheita; durante o transporte, armazenamento e comercialização.

Em vista do manejo diferenciado, a produção de tomate em ambiente protegido ou a campo, no sistema convencional, demanda cultivares bem adaptadas e que proporcionem o máximo de rendimento de produtos de elevado padrão de qualidade. Nesse contexto, cultivares de tomate do tipo longa vida tem aumentado a sua participação no mercado para consumo in natura, representando cerca de $70 \%$ do mercado (DELLA VECCHIA; KOCH, 2000).

Para obter o máximo de benefícios de cada um desses diferentes sistemas de cultivo, o conhecimento da interação genótipos $x$ ambientes é fundamental, pois a mesma ocorre quando se testam diversas cultivares em diferentes condições ambientais (SHIRAHIGE, 2009).

A existência da interação é uma dificuldade adicional à seleção e recomendação de genótipos, pois o melhor genótipo em um ambiente pode não o ser em outro (CRUZ; REGAZZI, 1997). Devido a isso, conforme relata Cruz e Carneiro (2003) a alternativa mais freqüentemente utilizada para amenizar a influência dessa interação é a recomendação de cultivares com ampla adaptabilidade e estabilidade. Cruz e Carneiro (2003) definem adaptabilidade como sendo a capacidade dos genótipos aproveitarem vantajosamente o estímulo do ambiente, enquanto que a estabilidade refere-se à capacidade dos genótipos mostrarem um comportamento altamente previsível em função do estímulo do ambiente.

Quando verificada a existência da interação significativa entre genótipos e ambientes, utilizam-se técnicas para identificar genótipos adaptados e estáveis a ambientes específicos (DIAS et al., 2009). Na identificação do genótipo ideal é necessária a realização de experimentos nas diferentes condições ambientais em que os genótipos serão avaliados para os caracteres de interesse (CARGNIN et al., 2006).

Apesar da importância da cultura do tomateiro, são poucos os experimentos que avaliaram a estabilidade de genótipos de tomate tanto para características quantitativas como qualitativas, podendo ser citados os de Poysa et al. (1986), Berry et al. (1988) e Ortiz e Izquierdo (1994). No Brasil, foram encontradas duas citações (GUALBERTO et al., 2002; PEIXOTO et al., 1999) sobre esse assunto.

Entre as metodologias utilizadas, o método centróide, baseado em componentes principais, representa a variação da performance dos genótipos nos ambientes em uma dispersão no plano, permitindo análise simultânea do desempenho de um número elevado de genótipos, facilitando a interpretação da interação (BARROS et al., 2008), pois baseia-se na comparação da distância cartesiana entre os genótipos e quatro referências ideais (ideótipos), que são: Ideótipo I - representa os ideótipos de máxima adaptabilidade geral, apresentando valores máximos observados para todos os ambientes estudados; Ideótipo II - representa os ideótipos de máxima adaptabilidade específica, apresentando máxima resposta em ambientes favoráveis e mínima resposta em ambientes desfavoráveis; Ideótipo III - representa os ideótipos com máxima resposta em ambientes desfavoráveis e mínima resposta em ambientes favoráveis; e Ideótipo IV - representa os ideótipos de mínima adaptabilidade, sendo aqueles que apresentam os menores valores em todos os ambientes estudados (ROCHA et al., 2005).

O conceito de adaptabilidade e estabilidade utilizado no método centróide diferencia dos demais métodos, uma vez que o genótipo de máxima adaptação específica não é aquele que apresenta bom desempenho nos grupos de ambientes favoráveis ou desfavoráveis, mas sim o genótipo que apresenta valores máximos para determinado grupo de ambientes (favoráveis e desfavoráveis) e mínimo para o outro conjunto (ROCHA et al., 2005).

Diante do exposto, o objetivo deste trabalho foi avaliar, com base na produtividade e na massa média de frutos comerciais, a adaptabilidade e estabilidade de genótipos de tomate de mesa comerciais e pré-comerciais do 
tipo longa vida em duas épocas de semeadura sob condições de temperatura elevada em Gurupi, estado do Tocantins.

\section{Material e métodos}

Foram realizados dois experimentos conduzidos em Gurupi, TO, no ano agrícola 2008/2009, no Campus Experimental da Fundação Universidade Federal do Tocantins, situado à latitude $11^{\circ} 43^{\prime} \mathrm{S}$ e longitude $49^{\circ} 15^{\prime} \mathrm{W}$ e altitude de 300 m, em um Latossolo Vermelho-Amarelo.

Foi utilizado o delineamento de blocos ao acaso com três repetições. Cada parcela foi constituída por uma fileira com oito plantas com espaçamento de $0,42 \mathrm{~m}$ entre plantas e $0,45 \mathrm{~m}$ entre linhas. O plantio foi realizado em casa de vegetação no verão (dezembro a março) e no campo durante o inverno (junho a setembro). Na Figura 1 estão os dados de temperatura média do período de realização dos experimentos.

Nas duas épocas foram avaliados 15 genótipos experimentais de tomateiro, sendo: quatro do tipo longa vida mutantes de amadurecimento rin comerciais e pré-comerciais: Tyler, Rebeca, Carmem e AF 13527; nove do tipo longa vida estrutural comerciais e pré-comerciais: Lumi, Débora Max, Michelli, Tammy, AF 12525, AF 11097, AF 13363, AF 13364 e AF 13525; e dois de frutos normais como testemunha: Santa Clara, que é a cultivar mais plantada no Brasil e Drica, cultivar melhorada para as condições do estado do Tocantins.

As sementes foram semeadas em casa de vegetação, diretamente em bandejas de isopor de 128 células, com mistura de substrato comercial Plantmax ${ }^{\circledR}$ e casca de arroz carbonizada na proporção $1: 1$.

Figura 1 - Dados de temperatura do período de cultivo de tomateiro do tipo longa vida e normal em duas épocas. UFT, Gurupi, TO, 2009

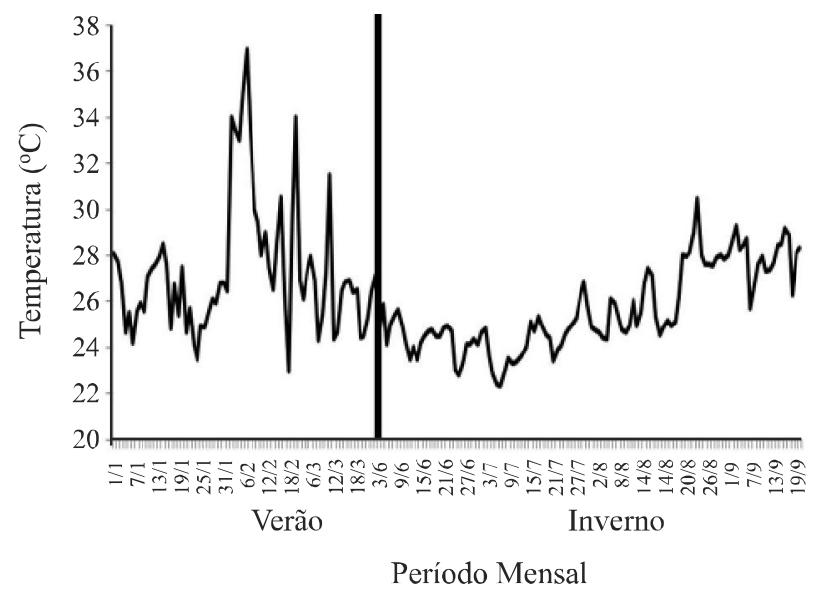

Em ambos os experimentos, as mudas foram transplantadas aos 25 dias após a semeadura (estádio de quatro a seis folhas definitivas). A adubação de plantio foi realizada de acordo com a recomendação para a cultura (ALVARENGA, 2004), com base nas propriedades químicas do solo nas duas épocas. O cultivo foi feito em sistema tutorado, utilizando irrigação por gotejamento. Semanalmente, as plantas foram desbrotadas para manter haste única e tutoradas individualmente.

Foram avaliadas a produtividade comercial $\left(\mathrm{t} \mathrm{ha}^{-1}\right)$ e massa média de frutos comerciais $\left(\mathrm{g}_{\text {fruto }}{ }^{-1}\right)$. Realizaramse análises de variância individuais seguidas de análises de variância conjunta, após teste de homogeneidade de variância, segundo Pimentel Gomes (1990). Contrastes não ortogonais foram calculados para comparar os grupos de tratamentos, permitindo avaliar e quantificar os efeitos dos backgrounds genéticos rin, estrutural e normal.

A análise de estabilidade fenotípica dos genótipos foi feita pelo método Centróide (ROCHA et al., 2005). Para utilização desse método, os ambientes foram classificados em favoráveis e desfavoráveis utilizando o índice ambiental como proposto por Finlay e Wilkinson (1963).

$$
I_{j}=\frac{1}{g} \sum_{i} Y_{i j}-\frac{1}{a g} Y \ldots
$$

em que: $Y_{\mathrm{ij}}$ é a média do genótipo i no ambiente j; $Y$. é o total das observações; $a$ é o número de ambientes; e $g$ é o número de genótipos.

\section{Resultados e discussão}

Para ambas as características verificou-se efeito significativo dos genótipos e da interação genótipos $x$ época (TAB. 1). É extremamente desejável que as cultivares obtidas pelos programas de melhoramento de plantas expressem seu potencial genético nos diferentes ambientes onde serão cultivadas (PENA et al., 2010). Portanto, há necessidade de se realizar uma pesquisa para identificar os materiais de maior adaptabilidade e estabilidade.

A produtividade comercial média dos genótipos nos dois ambientes avaliados atingiu 43,83 t.ha-1, com amplitude delimitada pelos híbridos Lumi (estrutural) e AF 13527 (rin) ambos longa vida, os quais apresentaram produtividades de $29,06 \mathrm{tha}^{-1} \mathrm{e} 59,05 \mathrm{tha}^{-1}$, respectivamente (TAB. 2). Os rendimentos dos genótipos avaliados diferiram estatisticamente, com destaque para aqueles que possuem o gene rin que tiveram os maiores valores, quando comparados, principalmente, com os de fruto normal.

Foi constatado aumento na produção comercial de frutos em ambos os grupos de tomate longa vida (rin e estrutural), conforme demonstra a estimativa do 
Tabela 1 - Resumo da análise conjunta de variância para produtividade comercial e massa média de frutos comerciais em genótipos de tomate tipo longa vida e normal em duas épocas de semeadura em Gurupi,TO, 2009

\begin{tabular}{lccc}
\hline \multirow{2}{*}{ F.V } & GL & \multicolumn{2}{c}{ QM } \\
\cline { 3 - 4 } & & Massa média de frutos comercial & Produtividade comercial \\
\hline Bloco/ Épocas & 4 & $139,69 \mathrm{~ns}$ & $185,56 \mathrm{~ns}$ \\
Genótipos & 14 & $529,76^{*}$ & $1373,7^{*}$ \\
Épocas & 1 & $24846,02^{* *}$ & $584,06 \mathrm{~ns}$ \\
Gx E & 14 & $875,4 * *$ & $591,36^{*}$ \\
Resíduo Médio & 56 & 233,44 & 350,04 \\
Média geral & & 43,83 & 114,62 \\
CV $(\%)$ & & 46,45 & 16,25 \\
\hline
\end{tabular}

*;** Significativo a $1 \%$ e $5 \%$ pelo teste de $\mathrm{F} ;{ }^{\text {ns }}$ - não significativo

Tabela 2 - Estimativas de médias para produção comercial de frutos e massa média de frutos comercial e estimativas de contrastes não ortogonais de interesse dos genótipos de tomate longa vida e normal em duas épocas de cultivo, UFT, Gurupi, TO, 2009

\begin{tabular}{|c|c|c|c|c|c|c|c|}
\hline \multirow{3}{*}{ Tratamentos } & & Inverno & Verão & \multirow{3}{*}{ Média } & Inverno & Verão & \multirow{3}{*}{ Média } \\
\hline & & \multicolumn{2}{|c|}{ Produção Comercial } & & \multirow{2}{*}{\multicolumn{2}{|c|}{$\begin{array}{l}\text { Massa Média de frutos } \\
\text { comercial }\left(\mathrm{g} \text { fruto }{ }^{-1}\right)\end{array}$}} & \\
\hline & Genótipos & \multicolumn{2}{|c|}{$\left(\mathrm{t} \mathrm{ha}^{-1}\right)$} & & & & \\
\hline Tyler & rin & $69,17 \mathrm{Ab}$ & $34,25 \mathrm{Bc}$ & 51,71 a & $127,11 \mathrm{Ab}$ & $125,11 \mathrm{Aa}$ & $126,11 \mathrm{a}$ \\
\hline Lumi & Estrutural & $25,49 \mathrm{Ae}$ & $32,64 \mathrm{Ac}$ & $29,06 \mathrm{~b}$ & $126,4 \mathrm{Ab}$ & $144,72 \mathrm{Aa}$ & $135,56 \mathrm{a}$ \\
\hline Debora Max & Estrutural & $65,34 \mathrm{Ab}$ & $2,3 \mathrm{Be}$ & $33,82 \mathrm{~b}$ & $100,44 \mathrm{Ac}$ & 73,76 Aa & $87,1 \mathrm{~b}$ \\
\hline Michelli & Estrutural & $77,96 \mathrm{Aa}$ & $19,46 \mathrm{Bd}$ & $48,71 \mathrm{a}$ & $164,06 \mathrm{Aa}$ & $134,13 \mathrm{Aa}$ & $149,095 \mathrm{a}$ \\
\hline Tammy & Estrutural & $36,27 \mathrm{Ad}$ & $33,26 \mathrm{Ac}$ & $34,76 \mathrm{~b}$ & $100,98 \mathrm{Bc}$ & $134,76 \mathrm{Aa}$ & $117,87 \mathrm{~b}$ \\
\hline Rebeca & $\operatorname{rin}$ & $62,29 \mathrm{Ab}$ & $35,47 \mathrm{Bc}$ & $48,88 \mathrm{a}$ & $97,18 \mathrm{Ac}$ & $110,82 \mathrm{Aa}$ & $104 \mathrm{~b}$ \\
\hline Carmem & $\operatorname{rin}$ & $75,54 \mathrm{Aa}$ & $25,22 \mathrm{Bc}$ & 50,38 a & $94,42 \mathrm{Ac}$ & $111,59 \mathrm{Aa}$ & $103,005 \mathrm{~b}$ \\
\hline AF 12525 & Estrutural & $25,39 \mathrm{Be}$ & $52,8 \mathrm{Aa}$ & $39,1 \mathrm{~b}$ & $104,03 \mathrm{Ac}$ & $111,59 \mathrm{Aa}$ & $107,81 \mathrm{~b}$ \\
\hline AF 11097 & Estrutural & $63,11 \mathrm{Ab}$ & $11,84 \mathrm{Bd}$ & $37,48 \mathrm{~b}$ & $138,44 \mathrm{Ab}$ & $122,62 \mathrm{Aa}$ & $130,53 \mathrm{a}$ \\
\hline AF 13363 & Estrutural & $49,72 \mathrm{Ac}$ & $27,03 \mathrm{Bc}$ & $38,37 \mathrm{~b}$ & $105,37 \mathrm{Ac}$ & $108,8 \mathrm{Aa}$ & $107,085 \mathrm{~b}$ \\
\hline AF 13364 & Estrutural & $72,59 \mathrm{Aa}$ & $42,05 \mathrm{Bb}$ & $57,32 \mathrm{a}$ & $89,85 \mathrm{Ac}$ & $109,01 \mathrm{Aa}$ & $99,43 \mathrm{~b}$ \\
\hline AF 13525 & Estrutural & $76,34 \mathrm{Aa}$ & $30,54 \mathrm{Bc}$ & $53,44 \mathrm{a}$ & $117,1 \mathrm{Ac}$ & $127,3 \mathrm{Aa}$ & $122,2 \mathrm{a}$ \\
\hline AF 13527 & $\operatorname{rin}$ & $85,94 \mathrm{Aa}$ & $32,16 \mathrm{Bc}$ & $59,05 \mathrm{a}$ & $100,63 \mathrm{Ac}$ & $125,15 \mathrm{Aa}$ & $112,89 \mathrm{~b}$ \\
\hline Santa Clara & Normal & $74,67 \mathrm{Aa}$ & $8,56 \mathrm{Be}$ & $41,61 \mathrm{~b}$ & $117,66 \mathrm{Ac}$ & $96,1 \mathrm{Aa}$ & $106,88 \mathrm{~b}$ \\
\hline Drica & Normal & $62,7 \mathrm{Ab}$ & $4,97 \mathrm{Be}$ & $33,83 \mathrm{~b}$ & $94,02 \mathrm{Bc}$ & $125,36 \mathrm{Aa}$ & $109,69 \mathrm{~b}$ \\
\hline \multicolumn{2}{|l|}{ Média dos Tratamentos } & 61,5 & 26,17 & 43,83 & 111,85 & 117,39 & 114,62 \\
\hline \multicolumn{8}{|c|}{ Estimativa dos contrastes de interesse } \\
\hline rin vs Estrutural & & $18,54^{*}$ & $3,78^{\mathrm{ns}}$ & $11,16^{*}$ & $-0,35^{\mathrm{ns}}$ & $-11,46^{\mathrm{ns}}$ & $-5,9^{\mathrm{ns}}$ \\
\hline rin vs Normal & & $4,55^{\mathrm{ns}}$ & $25,01 *$ & $14,78^{*}$ & $7,43^{\text {ns }}$ & $-1,0^{\mathrm{ns}}$ & $3,22^{\mathrm{ns}}$ \\
\hline Estrutural vs Normal & & $-13,99^{\text {ns }}$ & $21,22 *$ & $3,62 \mathrm{~ns}$ & $7,79^{\mathrm{ns}}$ & $10,45^{\mathrm{ns}}$ & $9,12^{\mathrm{ns}}$ \\
\hline
\end{tabular}

Médias seguidas pelas mesmas letras minúsculas na coluna, não diferem entre si pelo teste de Scott-Knott a $5 \%$. *; ns : Significativo ou não significativo pelo teste de Scheffé $(\mathrm{p}=0,05)$

contraste rin vs estrutural, rin vs normal e estrutural vs normal quando comparados aos genótipos do tipo mole
(TAB. 2). No período de inverno, apenas a estimativa de contraste rin vs estrutural foi significativa. No verão, 
as estimativas de contrastes foram significativas para os grupos rin vs Normal e estrutural vs normal.

A massa média de frutos comerciais é uma variável importante relacionada com a qualidade dos frutos, indicando diretamente o tamanho dos frutos. Para essa característica houve ampla variação nas duas épocas de avaliação para o conjunto de genótipos (TAB. 2).

Não houve diferença entre o grupo de genótipos que possuem o gene rin e o grupo de longa vida estrutural para os valores de massa média que, conforme pode ser constatado pela estimativa do contraste que foi negativa (TAB. 2).

O grupo rin proporcionou frutos com maior massa média de frutos quando comparado com o grupo normal. Não foi verificado efeito significativo do contraste rin vs normal (TAB. 2). A estimativa não significativa do contraste rin vs estrutural, rin vs normal e estrutural vs normal significa que o alelo rin e o tipo longa vida estrutural, não apresentaram resposta diferenciada entre si sobre a massa média de frutos, mesmo tendo ambas as constituições genotípicas contribuído para o aumento desses valores. Não houve diferença significativa para as estimativas de contrastes entre as épocas de cultivo.

Os genótipos apresentaram distribuiçãoheterogênea para a produtividade comercial e massa média de frutos comerciais (FIG. 2 e 3 ). Os pontos de maior proximidade a todos os quatro centróides possibilita uma recomendação de genótipos de adaptabilidade geral ou recomendação de genótipos de adaptabilidade específica a um subgrupo de ambientes (CARVALHO et al., 2002). Os genótipos Tyler; Rebeca; AF 13364; AF 13525 e AF 13527 foram classificados como sendo de adaptabilidade geral às duas épocas de avaliação, para a característica produtividade. Em relação à massa média de frutos comerciais, os genótipos mais adaptados foram: Tyler, Michelli e AF 11097. Para as duas características, os genótipos com adaptabilidade geral podem ser classificados como mais estáveis nos ambientes de avaliação. Entretanto, a maioria dos genótipos apresentaram centróides próximos à região central do gráfico, dificultando a classificação.

A classificação dos genótipos pelo método centróide é estimada a partir de estimativas obtidas do inverso do valor da distância entre um ponto aos quatro centróides, tendo-se assim o parâmetro de confiabilidade do agrupamento dos genótipos (ROCHA et al., 2005). Dessa maneira, um ponto eqüidistante aos quatro pontos referenciais apresenta valores de probabilidade de $25 \%$ de pertencer a qualquer um dos grupos e, portanto, quanto mais o valor de probabilidade diferir de $25 \%$, maior será a certeza em concluir o agrupamento do genótipo. Nesse sentido, Rocha et al. (2005), ressalta que valores de probabilidade próximos ou superiores a $50 \%$ indicam boa confiabilidade no agrupamento.
Figura 2 - Dispersão gráfica dos escores em relação aos dois primeiros componentes principais obtidos da análise da produtividade comercial de 15 genótipos de tomate longa vida e normal em duas épocas de cultivo em Gurupi, TO. Os quatro pontos numerados com algarismos romanos representam os centróides. 1 = Tyler; 2 = Lumi; 3 = Débora Max; $4=$ Michelli; $5=$ Tammy; 6 = Rebeca; 7 = Carmem; 8 = AF 12525; 9 = AF 11097; 10 $=\mathrm{AF} 13363 ; 11=\mathrm{AF} 13364 ; 12=\mathrm{AF} 13525 ; 13=\mathrm{AF} 13527 ; 14=$ Santa Clara; $15=$ Drica

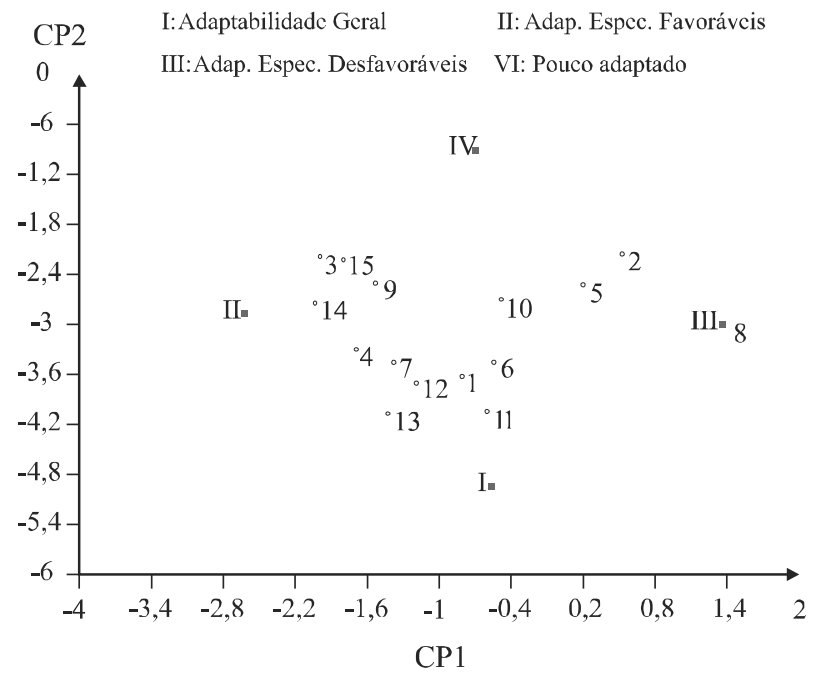

Figura 3 - Dispersão gráfica dos escores em relação aos dois primeiros componentes principais obtidos da análise de massa média de frutos comerciais 15 genótipos de tomate longa vida e normal em duas épocas de cultivo em Gurupi, TO. Os quatro pontos numerados com algarismos romanos representam os centróides. 1 = Tyler; $2=$ Lumi; 3 = Débora Max; $4=$ Michelli; $5=$ Tammy; 6 = Rebeca; 7 = Carmem; 8 = AF 12525; 9 =AF 11097; 10 $=\mathrm{AF} 13363 ; 11=\mathrm{AF} 13364 ; 12=\mathrm{AF} 13525 ; 13=\mathrm{AF} 13527 ; 14=$ Santa Clara; $15=$ Drica

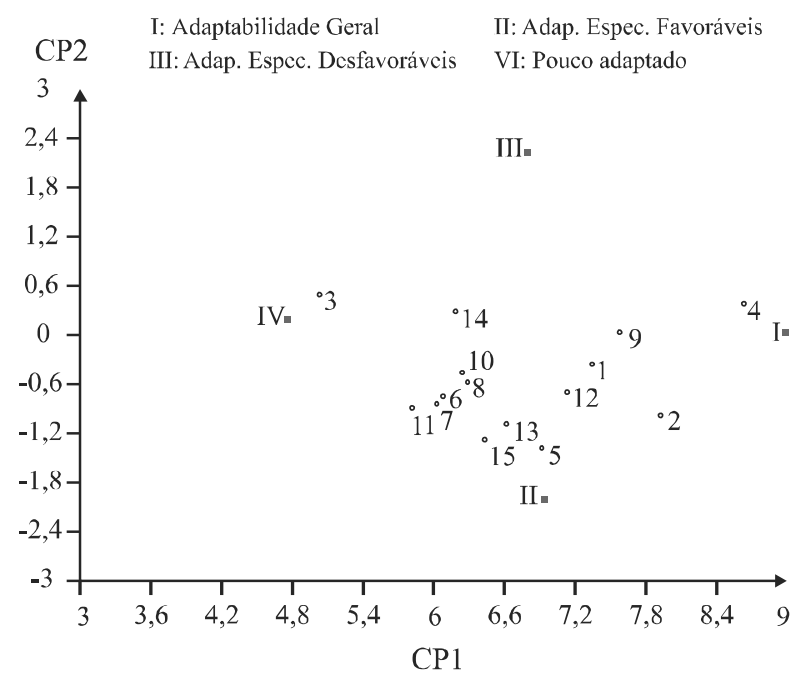


A classificação dos genótipos a um dos quatro grupos e a probabilidade associada a sua classificação são apresentadas nas Tabelas 3 e 4. Pelo método Centróide, para produtividade comercial $\left(\mathrm{t} \mathrm{ha}^{-1}\right)$, os genótipos: Tyler, Rebeca, AF 13364, AF 13525, AF 13527 foram classificados para condições ambientais amplas (grupo I) com destaque para os genótipos AF 13364 e AF 13527, além dos genótipos Tammy e Lumi que foram classificados como de adaptabilidade específica a ambientes desfavoráveis, por isso de baixa estabilidade.

Para massa média comercial de frutos houve ampla variação entre os genótipos para as duas épocas (TAB. 4), destacando-se Tyler, Michelli e AF 11097 que foram classificados como de máxima adaptabilidade geral (grupo I). Vale ressaltar que o genótipo Tyler foi o único classificado neste grupo também para produtividade (TAB. 3), mostrando que este pode ser cultivado nas duas épocas sem prejuízo na produtividade e na massa média de frutos comerciais.

Observa-se uma tendência de aumento na média de produtividade comercial e massa média de frutos comerciais dos genótipos de tomate à medida que estes se aproximam do centróide I (adaptabilidade geral), conforme Figuras 2 e 3 e Tabelas 3 e 4. De acordo com Rocha et al. (2005), quanto menor for a diferença entre um genótipo qualquer e o ideótipo I, menor será a diferença entre este e o genótipo de máximo desempenho em todos os ambientes, fazendo com que a adaptabilidade geral esteja necessariamente associada ao melhor desempenho e também à maior estabilidade.

Dos 15 genótipos, apenas um foi classificado como de mínima adaptabilidade geral (classe IV), para produtividade comercial e quatro para massa média de frutos comerciais. Nesse sentido, os genótipos com maior probabilidade de pertencer a essa classe foram AF 13363 para ambas as características, Débora Max, AF 13364 e Santa Clara para massa média de frutos comerciais (TAB. 3 e 4). Em relação à produtividade, seis genótipos foram classificados como de máxima adaptabilidade a ambientes favoráveis e aqueles com maior probabilidade de pertencer a essa classe foram Débora Max, Michelli, Carmem, AF 11097. Para massa média de frutos comerciais, destacaram-se os genótipos Lumi, Tammy, Rebeca, Carmem, AF 12525, AF 13525, AF 13527 e Drica. Gualberto et al. (2002), estudando o desempenho produtivo, adaptabilidade e estabilidade fenotípica de genótipos de tomateiro,

Tabela 3 - Estimativas de médias para produtividade comercial $\left(\mathrm{t} \mathrm{ha}^{-1}\right)$ e a classificação dos genótipos em um dos quatro grupos caracterizados pelos centróides e a probabilidade $(\mathrm{P})$ associada a sua classificação dos genótipos de tomate longa vida e normal em duas épocas de cultivo em Gurupi, TO, 2009

\begin{tabular}{lcccccc}
\hline \multirow{2}{*}{ GENÓTIPOS } & Média & Grupo & P (I) & P (II) & P (III) & P (IV) \\
\hline Tyler & 51,71 A & I & 0,3731 & 0,2586 & 0,1962 & 0,1721 \\
Lumi & 29,06 B & III & 0,1388 & 0,1308 & 0,4388 & 0,2916 \\
Debora Max & 33,82 B & II & 0,1707 & 0,4518 & 0,1445 & 0,233 \\
Michelli & 48,71 A & II & 0,2511 & 0,4549 & 0,1383 & 0,1557 \\
Tammy & 34,76 B & III & 0,1688 & 0,1539 & 0,4028 & 0,2745 \\
Rebeca & 48,88 A & I & 0,33 & 0,2375 & 0,2374 & 0,195 \\
Carmem & 50,38 A & II & 0,3105 & 0,3636 & 0,1599 & 0,166 \\
AF 12525 & 39,1 B & III & 0,0000 & 0,0000 & 1,0000 & 0,0000 \\
AF 11097 & 37,48 B & II & 0,2023 & 0,3834 & 0,1704 & 0,2438 \\
AF 13363 & 38,37 B & IV & 0,2198 & 0,2228 & 0,2757 & 0,2817 \\
AF 13364 & 57,32 A & I & 0,4901 & 0,2003 & 0,1735 & 0,1361 \\
AF 13525 & 53,44 A & I & 0,3752 & 0,305 & 0,1636 & 0,1562 \\
AF 13527 & 59,05 A & I & 0,4311 & 0,298 & 0,1391 & 0,1318 \\
Santa Clara & 41,61 B & II & 0,1626 & 0,5758 & 0,1121 & 0,1494 \\
Drica & 33,83 B & II & 0,1795 & 0,408 & 0,1573 & 0,2552 \\
\hline
\end{tabular}

${ }^{1 / E m}$ que: Ideótipo I = Adaptabilidade geral (++); Ideótipo II = Adaptabilidade especifica a ambientes favoráveis (+-); Ideótipo III = Adaptabilidade específica a ambientes desfavoráveis (-+); Ideótipo IV = Pouco adaptado (--) 
Tabela 4 - Estimativas de médias para massa média de frutos comerciais ( $\mathrm{g}$ fruto ${ }^{-1}$ ) e a classificação dos genótipos em um dos quatro grupos caracterizados pelos centróides e a probabilidade (P) associada a sua classificação dos genótipos de tomate longa vida e normal em duas épocas de cultivo em Gurupi, TO, 2009

\begin{tabular}{lccllll}
\hline \multirow{2}{*}{ GENÓTIPOS } & \multirow{2}{*}{ Média } & \multicolumn{5}{c}{ Centróide $^{1 /}$} \\
\cline { 3 - 6 } & & Grupo & P(I) & P(II) & P(III) & P(IV) \\
\hline Tyler & $126,11 \mathrm{~A}$ & I & 0,3017 & 0,2998 & 0,1995 & 0,199 \\
Lumi & $135,56 \mathrm{~A}$ & II & 0,3366 & 0,3468 & 0,1578 & 0,1588 \\
Debora Max & $87,1 \mathrm{~B}$ & IV & 0,078 & 0,1036 & 0,1168 & 0,7017 \\
Michelli & $149,095 \mathrm{~A}$ & I & 0,7006 & 0,099 & 0,1229 & 0,0776 \\
Tammy & $117,87 \mathrm{~B}$ & II & 0,1422 & 0,6079 & 0,1035 & 0,1464 \\
Rebeca & $104 \mathrm{~B}$ & II & 0,1632 & 0,3528 & 0,16 & 0,3239 \\
Carmem & $103,005 \mathrm{~B}$ & II & 0,1587 & 0,3659 & 0,1544 & 0,3211 \\
AF 12525 & $107,81 \mathrm{~B}$ & II & 0,1797 & 0,3418 & 0,1736 & 0,3049 \\
AF 11097 & $130,53 \mathrm{~A}$ & I & 0,3652 & 0,2315 & 0,224 & 0,1793 \\
AF 13363 & $107,085 \mathrm{~B}$ & IV & 0,1798 & 0,3162 & 0,181 & 0,3229 \\
AF 13364 & $99,43 \mathrm{~B}$ & IV & 0,1505 & 0,3471 & 0,1509 & 0,3516 \\
AF 13525 & $122,2 \mathrm{~A}$ & II & 0,2448 & 0,379 & 0,1721 & 0,2041 \\
AF 13527 & $112,89 \mathrm{~B}$ & II & 0,1653 & 0,4912 & 0,1344 & 0,209 \\
Santa Clara & $106,88 \mathrm{~B}$ & IV & 0,1856 & 0,2227 & 0,2422 & 0,3496 \\
Drica & $109,69 \mathrm{~B}$ & II & 0,1448 & 0,5311 & 0,1209 & 0,2032 \\
\hline
\end{tabular}

${ }^{1 /}$ Em que: Ideótipo I = Adaptabilidade geral (++); Ideótipo II = Adaptabilidade especifica a ambientes favoráveis (+-); Ideótipo III = Adaptabilidade específica a ambientes desfavoráveis (-+); Ideótipo IV = Pouco adaptado (--)

observaram que a cultivar Carmen apresentou ampla adaptabilidade a todos os ambientes estudados, uma vez que mostrou produtividade superior à média geral, e para a característica peso médio dos frutos. No presente trabalho, a cultivar Carmen apresentou um dos menores valores entre os materiais estudados.

Pelúzio et al. (2008), avaliando o desempenho, a adaptabilidade e a estabilidade de genótipos de soja em quatro épocas de semeadura em Gurupi-TO e Pelúzio et al. (2010) avaliando o rendimento de grãos e a adaptabilidade e estabilidade de cultivares de soja, em várzea irrigada, no Sul do Estado do Tocantins observaram que a metodologia Centróide é coerente com a de Eberhart e Russell, usada, também, no seu estudo, permitindo identificar, entre os genótipos avaliados, o de maior estabilidade e adaptabilidade. Barros et al. (2008), avaliaram a adaptabilidade produtiva de 30 genótipos de soja em seis ambientes, chegando a conclusões semelhantes às obtidas nesse trabalho. Gualberto et al. (2002) estudando o desempenho produtivo, adaptabilidade e estabilidade fenotípica de genótipos de tomateiro, observou que a cultivar Carmem apresentou rendimento superior ao da média geral dos ensaios, ocorrendo o mesmo comportamento neste trabalho com esta cultivar.

\section{Conclusões}

1. Os genótipos de tomate longa vida Tyler, Rebeca, AF 13364, AF 13525 e AF 13527 são promissores por apresentarem elevada produtividade de frutos, ampla adaptabilidade e alta estabilidade, sendo os mais recomendados para condições de temperatura elevada;

2. Para massa média dos frutos, os genótipos, longa vida, Tyler, Michelli e AF 11097, são os únicos que mostram ampla adaptabilidade e alta estabilidade;

3. Os genótipos que possuem o gene rin são mais produtivos que os de fruto normal no período de inverno.

\section{Agradecimentos}

Ao $\mathrm{CNPq}$, pela concessão da bolsa para desenvolvimento do trabalho e à SAKATA SEED SUDAMÉRICA Ltda, pela concessão das sementes dos genótipos utilizadas nos experimentos. 


\section{Referências}

ALVARENGA, M. A. C. Tomate: produção em campo, em casade-vegetação e em hidroponia. Lavras: UFLA, 2004, 400 p.

BARROS, H. B. et al. Análises paramétricas e não-paramétricas para determinação da adaptabilidade e estabilidade de genótipos de soja. Scientia Agraria, v. 09, n. 03, p. 299-309, 2008.

BERRY, S. Z. et al. Stability in fruit yield, soluble solids and citric acid of eight machine-harvested processing tomato cultivars in Northern Ohio. Journal of the American Society for Horticultural Science, v. 113, p. 604-608, 1988.

CÁ, J. A. et al. Híbridos de tomateiro longa-vida com frutos de maior intensidade de coloração. Pesquisa Agropecuária Brasileira, v. 41, n. 09, p. 1377-1384, 2006.

CARGNIN, A. et al. Interação entre genótipos e ambientes e implicações em ganhos com seleção em trigo. Pesquisa Agropecuária Brasileira, v. 41, n. 06, p. 987-993, 2006.

CARVALHO, H. W. L. et al. Adaptabilidade e estabilidade de cultivares de milho no Nordeste brasileiro no triênio de 1998 a 2000. Pesquisa Agropecuária Brasileira, v. 37, n. 11, p. 1581-1588, 2002.

CRUZ, C. D.; REGAZZI, A. J. Modelos biométricos aplicados ao melhoramento genético. Viçosa: UFV, 1997, 390 p.

CRUZ, C. D.; CARNEIRO, P. C. S. Modelos biométricos aplicados ao melhoramento de plantas. 3. ed. Viçosa: UFV, 2003. 585 p.

DELLA VECCHIA, P. T.; KOCH, P. S. Tomates longa vida: O que são, como foram desenvolvidos?. Horticultura Brasileira, v. 18, n. 01, p. 3-4, 2000.

DIAS, F. T. C. et al. Adaptabilidade e estabilidade fenotípica para o caráter rendimento de grãos em cultivares de soja para o Estado do Ceará. Revista Ciência Agronômica, v. 40, n. 01, p. 129-134, 2009.

FINLAY, K. W.; WILKINSON, G. N. The analysis of adaptation in plant-breeding programme. Australian Journal of Agricultural Research, v. 14, n. 06, p. 742-754, 1963.
GUALBERTO, R.; BRAZ, L. T.; BANZATTO, D. A. Produtividade, adaptabilidade e estabilidade fenotípica de genótipos de tomate sob diferentes condições de ambiente. Pesquisa Agropecuária Brasileira, v. 37, n. 01, p.81-88, 2002a.

ORTIZ, R.; IZQUIERDO J. Yield stability differences among tomato genotypes grown in Latin America and the Caribbean. HortScience, v. 29, n. 10, p. 1175- 1177, 1994.

PEIXOTO, N. et al. Rendimento de cultivares de tomate para processamento industrial em Goiás. Horticultura Brasileira, v. 17, n. 01, p. $54-57,1999$.

PELÚZIO, J. M. et al. Adaptabilidade e estabilidade de cultivares de soja em várzea irrigada no Tocantins. Revista Ciência Agronômica, v. 41, n. 03, p. 427-434, 2010.

PELÚZIO, J. M. et al. Adaptabilidade e estabilidade de cultivares de soja em quatro épocas de semeadura no sul do Estado do Tocantins. Revista Ceres, v. 55, n. 01, p. 34-40, 2008.

PENA, M. A. A. et al. Adaptabilidade e estabilidade de genótipos de tomateiro sob cultivo em solos de terra firme e várzea da Amazônia infestados por Ralstonia Solanacearum. Bragantia, v. 69 , n. 01 , p. 27-37. 2010.

PIMENTEL-GOMES, F. Curso de Estatística Experimental. 13. ed. Piracicaba: Nobel, 1990. 468 p.

POYSA, V. W. et al. Genotypeenvironment interactions in processing tomatoes in Ontario. Journal of the American Society for Horticultural Science, v. 111, p. 293-297, 1986.

ROCHA, R. B. et al. Avaliação do método centróide para estudo de adaptabilidade ao ambiente de clones de Eucalyptus grandis. Ciência Florestal, v. 15, n. 03, p. 255-266, 2005.

SHIRAHIGE, F. H. Produtividade e qualidade de híbridos de tomate (Solanum lycopersicum L.) dos segmentos Santa Cruz e Italiano em função do raleio de frutos, em ambiente protegido. 2009. 80f. Dissertação (Mestrado em Agronomia). Escola Superior de Agricultura "Luiz de Queiroz", Piracicaba. 